\title{
Interlaminar fatigue crack growth behavior of MWCNT/carbon fiber reinforced hybrid composites monitored via newly developed acoustic emission method
}

\author{
G. Romhány*, G. Szebényi \\ Department of Polymer Engineering, Faculty of Mechanical Engineering, Budapest University of Technology and \\ Economics. Műegyetem rkp 3., H-1111, Budapest, Hungary
}

Received 8 November 2011; accepted in revised form 29 January 2012

\begin{abstract}
The aim of this research was the investigation of the effect of carbon nanotube addition on the mode I interlaminar fatigue properties of carbon fiber reinforced composites. The authors developed a localization methodology to track the interlaminar fatigue crack front using the acoustic emission (AE) technique. According to the test evaluation the carbon nanotube reinforcement decreased the crack propagation rate by $69 \%$ compared to the composite containing no nanotubes. Besides that, the fatigue life also increased significantly, the nanotube reinforced composite could withstand 3.8-times more cycles to failure than the unfilled matrix composite.
\end{abstract}

Keywords: fracture and fatigue, delamination, carbon nanotube, acoustic emission, hybrid nanocomposite

\section{Introduction}

High performance polymer composites are subjected to fatigue loading in most of their applications (vehicles, wind turbines, etc.). One of the common damage modes caused by such loadings is delamination, the separation of the adjacent layers. To describe the susceptibility to delamination various parameters can be used, one of these is interlaminar fracture toughness. From the three crack opening modes (opening mode (mode I), sliding mode (mode II), tearing mode (mode III)), the opening mode (mode I) is the most common, and therefore (besides mode II) the most intensively investigated in the literature. The knowledge of this material property can be useful for material selection and mechanical design in case of product development, and for the comparison of material types, qualification in case of material development. Because of these aspects it is important to investi- gate the interlaminar toughness of composites at both static and cyclic loading.

A part of the numerous publications in the field of quasistatic interlaminar crack propagation tests dealt with the effect of test parameters (for example: test speed [1]), laminate layup structure [2-6], others have characterized the effect of fillers/reinforcing materials on the fracture toughness (for example: carbon nanofiber/carbon fiber in epoxy $[7,8]$, glass fiber in unsaturated polyester [9], carbon nanotube/carbon fiber in epoxy [10], fluoride functionalized carbon nanotubes/carbon fibers in epoxy [11], amine functionalized carbon nanotubes/glass fibers in epoxy [12], carbon nanotubes grown radially from vapor on the surface of carbon fiber in epoxy [13], vapor grown carbon fibers/carbon fibers in epoxy [14], clay nanoparticles/carbon fibers in epoxy [15-17], halloysite nanotubes/carbon fibers in epoxy [18]). All of the papers utilizing nanoparti-

\footnotetext{
${ }^{*}$ Corresponding author, e-mail: romhany@pt.bme.hu
}

(c) BME-PT 
cle filling report increases from some to $300 \%$ in interlaminar fracture properties (for example: $G_{\mathrm{IC}}$ or $\left.G_{\mathrm{IIC}}\right)$. This increase has been explained with new failure modes (like the pullout of nanotubes), the formation of covalent bonds between the fiber and the matrix provided by functionalized nanotubes, the deflection of the crack front, and thereby the increase of the energy dissipation (indicated by the rougher, tougher fracture surface) caused by the nanoparticles.

Almost no results are available from interlaminar fatigue tests, because of the complexity and time consumption of these tests. Argüelles et al. [19] demonstrated that fatigue crack initiation is strongly influenced by the production technology (film thickness, resin content etc.), so a large number of tests have to be performed because of the high standard deviation. Hojo et al. [20] showed, that the thickness of the middle layer does not significantly affect the interlaminar properties in mode I crack propagation in contrast with mode II, where a thicker layer caused significant improvement. Hojo et al. [21] successfully increased the cyclic interlaminar fracture toughness both by the polyamide filled and by ionomeric middle layer.

After their discovery in 1991 carbon nanotubes came into focus of interest not only in the field of material science, but also almost all research areas. Researchers are trying to exploit the unique properties of carbon nanotubes in numerous applications, like in electronic components [22], fuel cells [23] and last but not least in the field of material science as new structural materials $[24,25]$. In our previous work we [26] investigated the effect of carbon nanotube reinforcement on the static mode I interlaminar fracture toughness of carbon fiber/epoxy laminates. Some papers indicate that carbon nanotubes could provide good results also in case of cyclic loading [27, 28], hinder the fatigue crack growth [29], improve the fatigue resistance of conventional fiber reinforced composites [30]. The aim of our present research is to investigate the effect of carbon nanotube reinforcement on the cyclic mode I interlaminar fracture toughness of the same material and to develop an acoustic emission localization based crack tracking method capable of crack propagation tracking during fatigue testing.

\section{Materials and methods}

\subsection{Materials}

Eporezit FM20 (P+M Polimerkémia Kft., Budapest, Hungary, Hungary) epoxy resin with Eporezit T16 curing agent was used as the matrix of the composite laminates, the mixing weight ratio was 100:20 according to the producer specifications.

As fiber reinforcement Zoltek (Nyergesújfalu, Hungary) PX35FBUD0300 unidirectional carbon fabric, consisting of Panex35 50k (surface weight $309 \mathrm{~g} / \mathrm{m}^{2}$ ) tows was used.

Bayer Baytubes ${ }^{\circledR}$ BT150 HP (Leverkusen, Germany) multiwalled carbon nanotubes (MWCNTs) were used as filler in one portion of the matrix. The nanotubes were produced in a CVD based catalytic process resulting in an average outer diameter between $13-16 \mathrm{~nm}$, length above $1 \mu \mathrm{m}$ and carbon purity above $99 \%$ according to the manufacturer.

\subsection{Composite preparation}

Because our previous static double cantilever beam (DCB) measurements [26] showed that significant interlaminar mechanical property increase could be achieved only up to 0.3 weight $\%$ nanotube content, 0.3 weight $\%$ nanotube reinforced and unreinforced specimens have been studied. The nanotube content used in this research has been selected based only on static results, so in our further work we are planning to obtain the optimal nanotube content for cyclic properties. The nanotubes were dispersed in the epoxy resin by three roll milling on an Enrico Molteni CIEM (Senago, Italy) three roll mill in 4 pass troughs. In their raw form the nanotubes form aggregates with a diameter of some millimeters, so not only their proper dispersion, but also the milling of these aggregates was of key importance. To characterize the effectiveness of the milling, fineness of grind measurements, common in case of dispersion of pigments, were carried out after the second, third, and fourth pass through. The maximum particle sizes were 15,10 and below $10 \mu \mathrm{m}$ respectively, which is the lowest measurable particle size of the equipment. There was no significant difference between result of the third and the fourth pass through, so probably it was the lowest achievable particle size by the given equipment.

Because well dispersed nanotubes cause an order of magnitude increase in resin viscosity [31], hand 
lamination was selected combined with pressing to achieve reproducible quality and uniform laminate thickness.

The $4 \mathrm{~mm}$ thick laminates were produced by hand lamination of 10 plies of unidirectional carbon fabric impregnated with the resin. A $50 \mu \mathrm{m}$ thick PET film was used as a delamination initiator insert in the center plane (between the $5^{\text {th }}$ and $6^{\text {th }}$ lamina) of the laminates. Both sides of the film were coated with mould release agent to minimize adhesion between the film and the matrix of the composite. To avoid voids, the laminate was rolled after every two plies.

To achieve uniform thickness and fiber content, to remove the excess resin, the laminates were pressed with two $4 \mathrm{~mm}$ thick steel plates placed as spreaders next to the laminates in the press. The laminates were cured for 4 hours at $60^{\circ} \mathrm{C}$ after the pressing in a Heraeaus UT20 (Thermo Fisher Scientific, Waltham, MA, USA) drying oven.

\subsection{Specimen preparation}

$210 \mathrm{~mm}$ long, $25 \mathrm{~mm}$ wide and $4 \mathrm{~mm}$ thick specimens according to ASTM D 5528 - 01 were cut from the laminates, the length of the delamination initiator was $65 \mathrm{~mm}$. The edges of each specimen was coated just ahead of the insert with a thin layer of water-based typewriter correction fluid to aid the visual detection of delamination propagation. $100 \mathrm{~mm}$ length of the specimens was marked with thin vertical lines every $2 \mathrm{~mm}$ from the insert to help the recording of the crack front position. Steel load hinges were mounted on the top and the bottom of each specimen using Sikadur 330 (Sika, Germany) adhesive.

\subsection{Fatigue mode I interlaminar crack propagation test}

Interlaminar fatigue tests were performed on DCB specimens using an Instron 8872 (Norwood, USA) servo-hydraulic universal, computer controlled loading frame with Instron Fasttrack 8800 control and data acquisition unit and an Instron Dynacell $1 \mathrm{kN}$ load cell. The applied load was sinusoidal with a frequency of $2 \mathrm{~Hz}$, a maximal load of $\left(P_{\max }\right)$ $70 \mathrm{~N}$ and a stress factor of $(R) 0.2 .10-10$ specimens were tested from the composite and the carbon nanotube reinforced hybrid composite.

\subsection{Acoustic emission}

The acoustic emission signals originating from the crack propagation were recorded by Micro30S (Physical Acoustic Corporation, USA) sensors in the frequency range from 100 to $600 \mathrm{kHz}$, and stored by a Sensophone AED-40 (Gereb and Co., Ltd., Budapest, Hungary) device. Logarithmic amplification was applied. The threshold was set to $30 \mathrm{~dB}$ to filter out ambient noises, and the reference voltage of the test device was $1 \mu \mathrm{V}$. Two AE sensors were fixed on the surface of the specimens at given positions, $120 \mathrm{~mm}$-s from each other, the distance between the first sensor and the artificial initial delamination was $20 \mathrm{~mm}$. Before the tests, the sound velocity in the specimen, necessary for the localization, was measured. The sensors were fixed to the specimen surface with bee wax, which functioned as a coupling material and as an adhesive. Using one of the sensors as an emitter the device recorded the detection time of the signal. With the sensor distance known, the device calculated the AE signal propagation speed $(9000 \mathrm{~m} / \mathrm{s})$. The test setup can be seen in Figure 1.

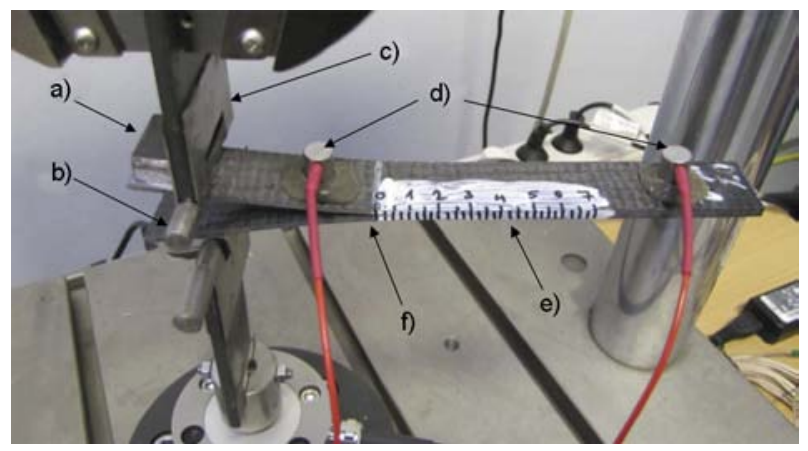

Figure 1. The DCB test setup a) load block, b) fixing pin, c) adapter hinge, d) AE sensors, e) scale, f) test specimen

\subsection{Transmission electron microscopy (TEM)}

$80 \mathrm{~nm}$ thick slices of the prepared specimens were investigated by TEM. The slices had been cut by a Leica Ultramicrotome EMUC6 (Wetzlar, Germany) microtome. The micrographs were taken using a FEI Morgani 268D (Hillsboro, USA) TEM.

\section{Result and discussion}

To characterize the dispersion of the carbon nanotubes in the matrix, TEM micrographs were taken of the thin slices of the matrix of the hybrid composite specimens (Figure 2). In the micrographs 


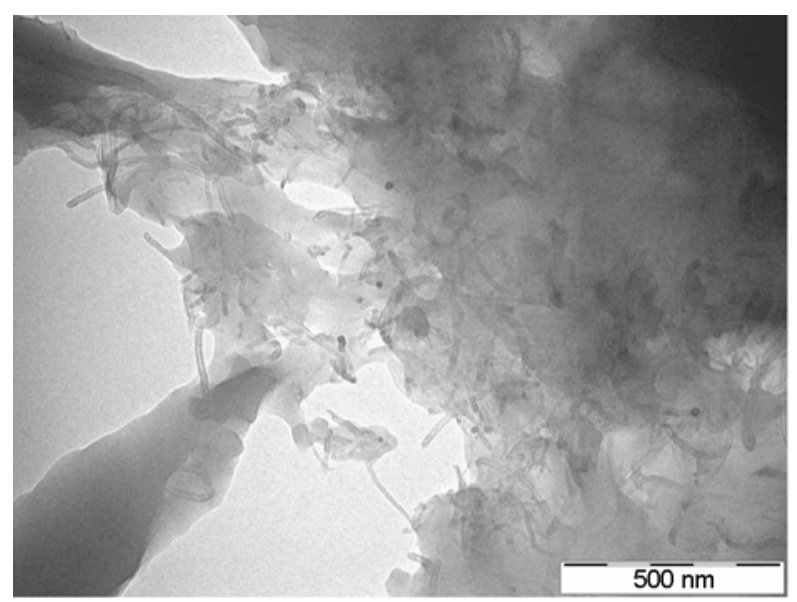

a)

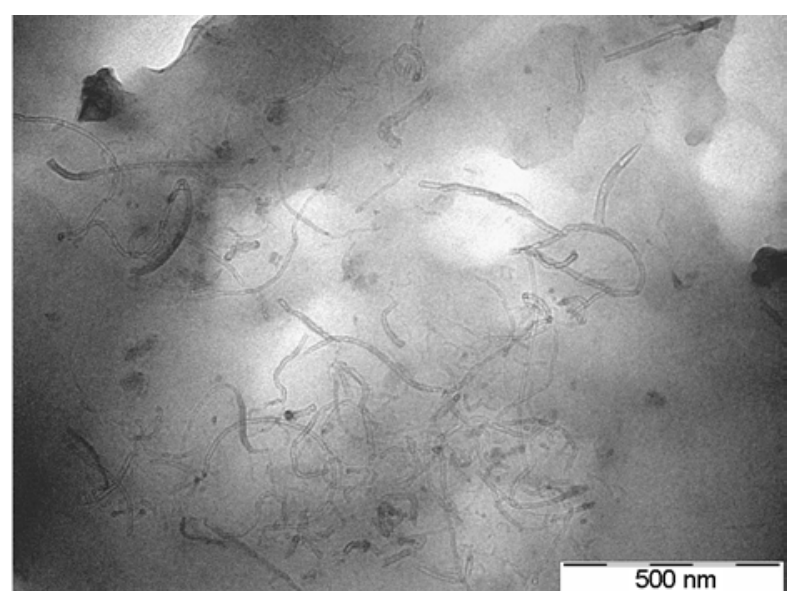

b)

Figure 2. TEM micrographs of the matrix of a hybrid composite specimen (two positions of the same specimen, a and b)

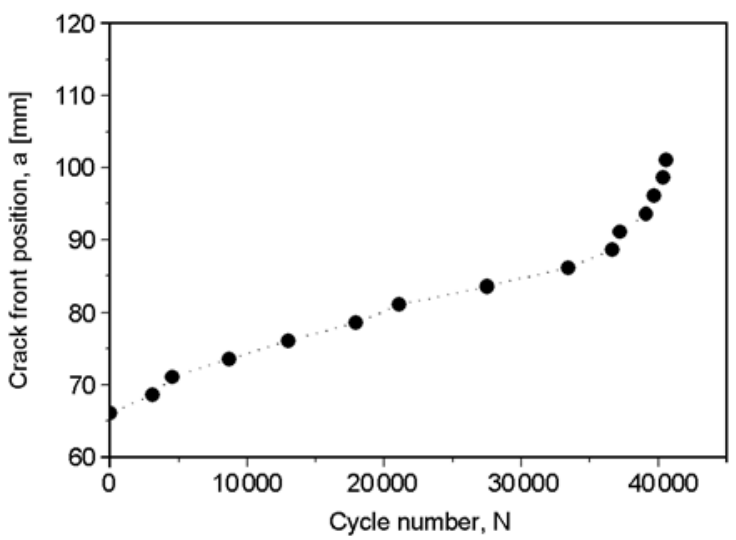

Figure 3. Crack front position - cycle number diagram of a 0.3 weight $\%$ nanotube filled hybrid composite specimen (obtained from visual observation)

well dispersed carbon nanotubes can be observed, so the mixing was effective.

The crack front position values were recorded as a function of cycle number by visual observation. A typical crack front position vs. cycle number curve can be seen in Figure 3.

The positions of the AE signal sources were also localized. The localized signal source positions from the fatigue test of a 0.3 weight $\%$ nanotube reinforced hybrid composite are presented in Figure 4. The localized AE signals almost completely cover the range between the two microphones. This can be explained by two factors. Firstly, the vibration of the fatigue tester provided signals originating from external sources. Secondly, the AE signal wave reflected sevaral times from the walls of the narrow specimen, generating signals from invalid sources.

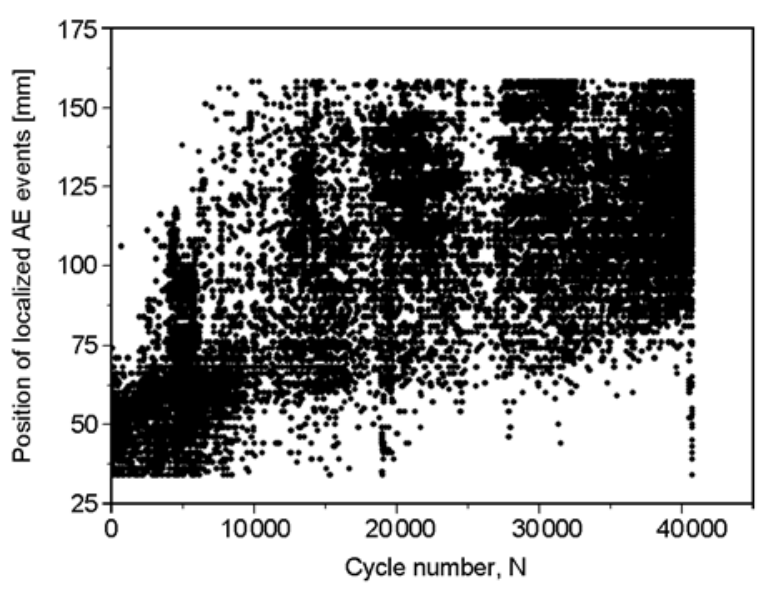

Figure 4. Localized AE signals from the fatigue test of a 0.3 weight $\%$ nanotube reinforced hybrid composite (the origin of the coordinate system is the line of loading; same specimen as in Figure 3)

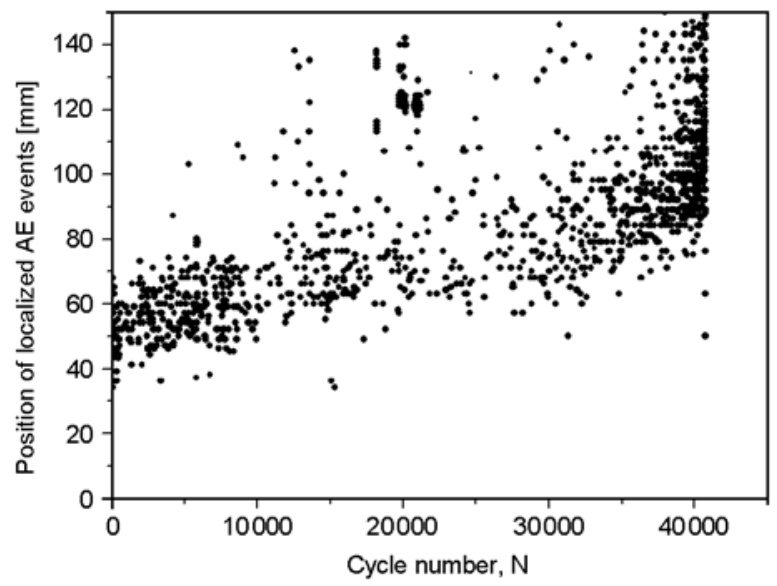

Figure 5. Localized AE signals from the fatigue test of a 0.3 weight $\%$ nanotube reinforced hybrid composite after the $60 \mathrm{~dB}$ amplitude filtering (the origin of the coordinate system is the line of loading; same specimen as in Figure 3 and 4) 


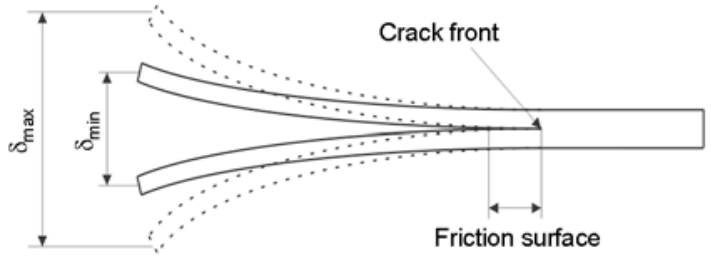

Figure 6. Friction surface of a DCB fatigue test specimen

To be able to track the crack front propagation, we have developed the following two step method. Supposing that the larger the amplitude of an AE signal is, the higher is the probability, that it originates from the actual crack propagation, in the first step we have performed an amplitude filtering to filter invalid AE signals (Figure 5). It can be observed that the strip of events representing the crack propagation narrowed down significantly, and the trend of crack propagation is somewhat clearer.

The large number of signals deviating from the trend even after filtering suggests, that some disturbing effects are still present. One such effect can be that the two separated parts of the specimen contact in each cycle, generating false AE signals through friction behind the crack front (Figure 6).

In the second step we averaged the localized signals by the following method. The initial position of the crack front is known. We kept the signals in a $-\Delta L-+\Delta U$ window from this point. $-\Delta L$ corresponds to the signals behind and $+\Delta U$ in front of the crack front. If a given $X$ number of AE signals was collected in this window, their crack position and cycle number average has been calculated and used as the actual crack position (Figure 7). To define the next crack front position signals in the $-\Delta L-+\Delta U$

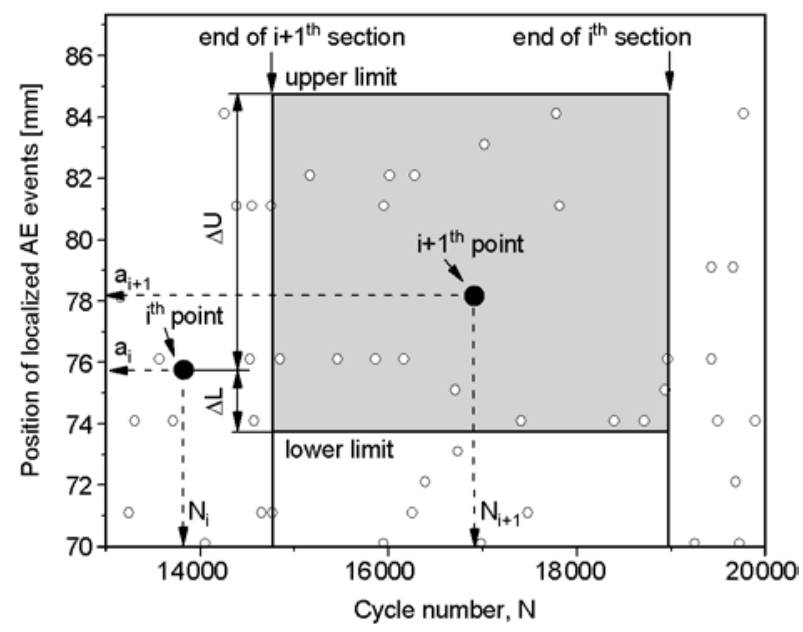

Figure 7. Method for calculating the averaged crack position in a given point (for same specimen as in Figure 3-5) window from this point had been collected until the number of collected signals reached $X$. Because of the dimension of the AE sensors the localization of signals from sources also forms a patch around the crack front, because of this, signals behind the crack front also have to be collected. The window size behind the crack front can be set by the $-\Delta L$ parameter. If $-\Delta L$ is set to a lower value than $+\Delta U$, the false signals generated by the friction between the two delaminated specimen halves can be filtered. $-\Delta L$ was set to $2 \mathrm{~mm},+\Delta U$ was set to $9 \mathrm{~mm}$ according to the comparison with the visual crack tracking results. The number of signals used for the averaging has to be high enough to get a statistically correct average value, but more points of the crack propagation can be acquired if we set the number lower. The selection of the right $\Delta L, \Delta U$ and $X$ can be therefore handled as an optimum finding task. In our case $X$ (the number of collected AE signals to be averaged for one crack position) was set to 17 .

The comparison of the crack front positions obtained from the AE measurement followed by the averaging method and recorded visually is presented in Figure 8. It can be observed that the crack propagation obtained by the two methods is similar in the stable crack propagation stage, larger differences only occur after the crack propagation becomes unstable, but the highest difference remains below 5 $\mathrm{mm}$. This difference can be explained by the troublesome visual tracking of the fast moving crack in the unstable stage. According to the results visual crack tracking can be superseded by the developed $\mathrm{AE}$ method.

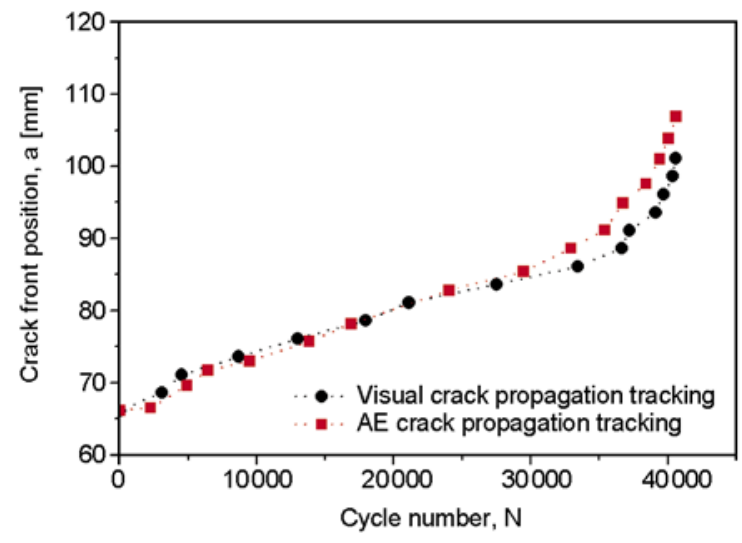

Figure 8. Comparison of the crack tracking results obtained by $\mathrm{AE}$ and visual crack tracking of the fatigue test of a 0.3 weight $\%$ nanotube filled hybrid composite specimen 


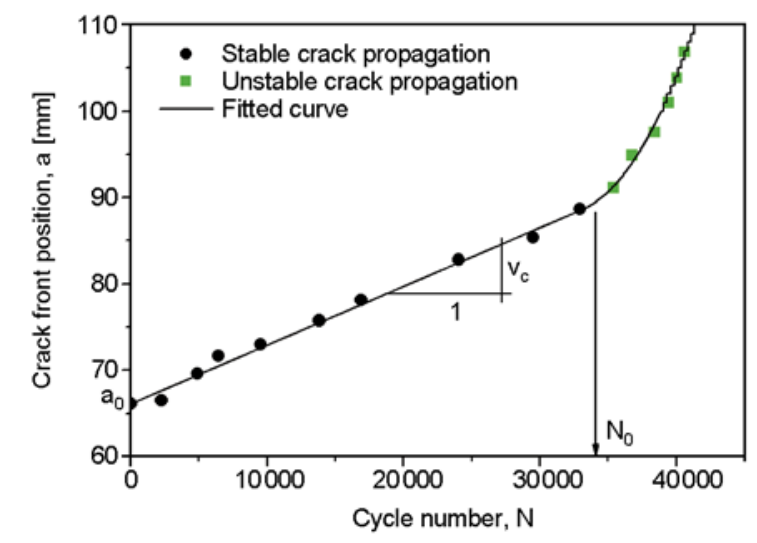

Figure 9. The fitted function for obtaining the stable crack propagation rate of a 0.3 weight $\%$ nanotube filled hybrid composite specimen

In case of fatigue testing one way of comparison of failure processes is the comparison of the crack propagation rates in the stable stage. To define the stable-unstable transition and obtain the crack propagation rate a five parameter curve Equation (1) was fitted to the measured points (Figure 9):

$a(N)=a_{0}+v_{\mathrm{c}} \cdot N+a_{\mathrm{nl}}(N)$

$a_{\mathrm{nl}}(\mathrm{N})=\left\{\begin{array}{l}k \cdot\left(N-N_{0}\right)^{\mathrm{n}} \quad \text { if } N>N_{0} \\ 0, \quad \text { otherwise }\end{array}\right.$

In the diagram it can be observed, that after a specific cycle number the crack propagation becomes unstable, followed by the catastrophic failure of the specimen. The stable-unstable transition was pinpointed by the $N_{0}$ parameter. The slope of the first, linear section, $\left(v_{\mathrm{c}}\right)$ defines the crack propagation rate in the stable stage. Because the maximum load and the specimen geometry were the same in all

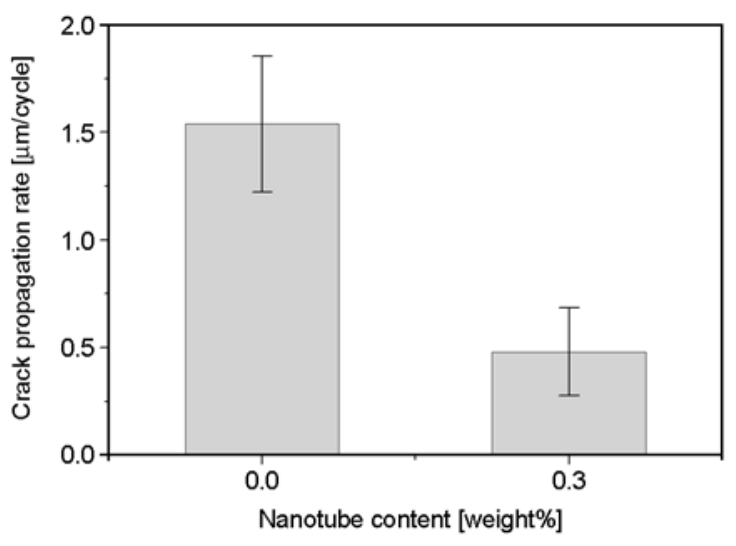

Figure 10. Comparison of the stable crack propagation rates of the 0 and 0.3 weight $\%$ nanotube content composites (data obtained from the test of 1010 specimens) cases during fatigue testing, the crack propagation rates can be compared. The comparison of the crack propagation rates of the composite and hybrid composite can be seen in Figure 10. (deviations in the figure correspond to double standard deviation).

According to the test results, the carbon nanotube reinforcement has decreased the crack propagation rate in the stable section by $69 \%$ compared to the composite not containing nanotubes.

With the crack propagation data the maximum cyclic strain energy release rate can be calculated by Equation (2) described in the ASTM 5528 standard:

$G_{\text {Imax }}=\frac{3}{2} \frac{P_{\max } \delta_{\max }}{a b}$

where $P_{\max }$ is the maximum load, $\delta_{\max }$ is the crack opening displacement at maximum load, $a$ is the crack front position from measured from the point of loading, $b$ is the specimen thickness.

The obtained $G_{\text {Imax }}$ values at 6 different crack front positions in $5 \mathrm{~mm}$ steps in the whole failure process can be seen in Figure 11 (deviations in the figure correspond to double standard deviation).

According to the results the $G_{\text {Imax }}$ values were in average $17 \%$ higher than in case of the composite without nanotubes. This can be explained by the lower crack opening displacement at a given load in case of the carbon nanotube reinforced composites. The crack opening displacement of a DCB specimen can be divided into two components. One of the components is the curved deformation of the delaminated specimen halves, the other is the deformation of the middle resin layer (Figure 12).

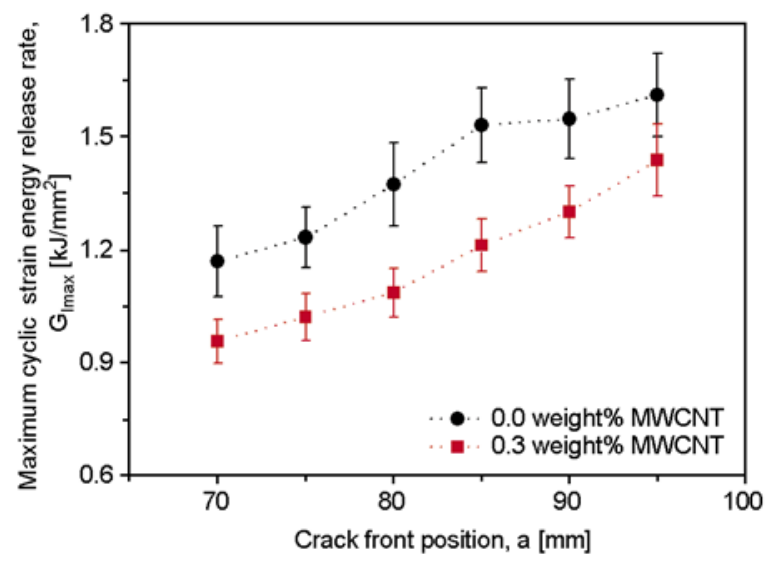

Figure 11. The maximum cyclic strain energy release rate values of the 0 and 0.3 weight $\%$ nanotube content composites at different crack front positions (data obtained from the test of 10-10 specimens) 


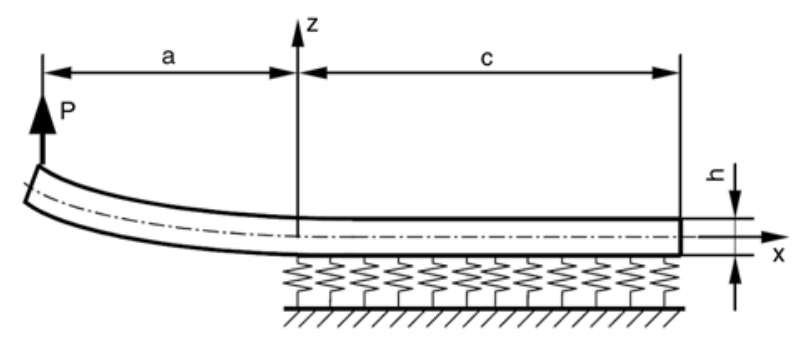

Figure 12. Mechanical half-model of a DCB specimen [32]

Previous tests showed no significant difference in the bending modulus of elasticity between the composites and the 0.3 weight $\%$ carbon nanotube reinforced composites [33], so the difference in the crack opening displacement of the DCB specimens during fatigue test can be mainly caused by the smaller deformation of the resin film. The stress peak emerging at the crack front at lower displacement will be lower in case of the carbon nanotube reinforced hybrid composites. This mechanism significantly decreases the rate of interlaminar crack propagation during fatigue testing. The individual $G_{\text {Imax }}$ values give no information about the advancement of the failure process (which is the most important in fatigue testing), they can be only interpreted together with the crack propagation rate and cycles to failure values. The cycle to failure results (cycles elapsed to the complete split of the specimens) are presented in Figure 13 (deviations in the figure correspond to double standard deviation).

According to our results, although with high deviation (which is acceptable in case of interlaminar fatigue tests), 0.3 weight $\%$ carbon nanotube reinforcement has increased the cycles to failure of the composites significantly, to 3.8 times the cycles withstood by the composites without nanotubes.

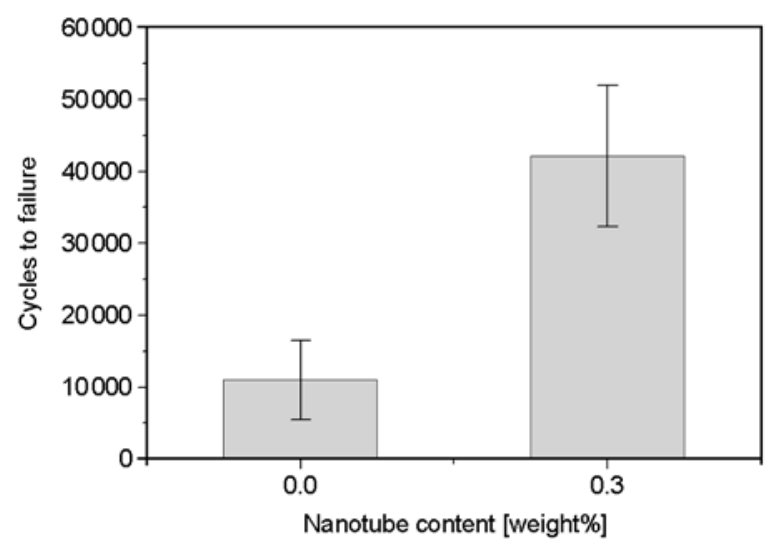

Figure 13. Cycles to failure of the 0 and 0.3 weight $\%$ nanotube content composites (data obtained from the test of 10-10 specimens)

\section{Conclusions}

The aim of this study was to investigate the effect of carbon nanotube filling on the interlaminar fatigue properties of composite laminates. In our previous work it was demonstrated, that in static DCB tests the best interlaminar mechanical properties can be obtained at 0.3 weight $\%$ carbon nanotube filling, so this content has been selected for the fatigue tests. According to the fatigue test results it can be declared that with 0.3 weight $\%$ carbon nanotube filling of the matrix of a carbon fiber reinforced composite:

- the cycles to failure increased to 3.8 times the original value,

- the crack propagation rate decreased by $69 \%$,

- the carbon nanotubes reinforced the interlaminar resin layer, which resulted in lower crack opening displacement at a given load, resulting in lower maximum cyclic strain energy release rate. The test results showed, that even with the addition of 0.3 weight $\%$ proportion of carbon nanotubes a more fatigue resistant, reliable material can be produced.

Besides these results, we have developed a new acoustic emission localization based crack tracking algorithm, capable of the replacement of visual crack propagation tracking.

\section{Acknowledgements}

The authors are thankful for József Hári, Dr. Károly Renner, the BME Laboratory of Plastics and Rubber Technology and the Chemical Research Center of the Hungarian Academy of Sciences for the preparation of the TEM micrographs. This work was supported by Hungarian Scientific Research Fund (OTKA F67897). This work is connected to the scientific program of the 'Development of quality-oriented and harmonized $\mathrm{R}+\mathrm{D}+\mathrm{I}$ strategy and functional model at BME' project. This project is supported by the New Széchenyi Plan (Project ID: TÁMOP-4.2.1/B-09/1/KMR2010-0002).

\section{References}

[1] Kusaka T., Hojo M., Mai Y-W., Kurokawa T., Nojima T., Ochiai S.: Rate dependence of mode I fracture behaviour in carbon-fibre/epoxy composite laminates. Composites Science and Technology, 58, 591-602 (1998).

DOI: 10.1016/S0266-3538(97)00176-0

[2] Solaimurugan S., Velmurugan R.: Influence of inplane fibre orientation on mode I interlaminar fracture toughness of stitched glass/polyester composites. Composites Science and Technology, 68, 1742-1752 (2008). DOI: $10.1016 /$ j.compscitech.2008.02.008 
[3] Velmurugan R., Solaimurugan S.: Improvements in mode I interlaminar fracture toughness and in-plane mechanical properties of stitched glass/polyester composites. Composites Science and Technology, 67, 6169 (2007).

DOI: $10.1016 /$ j.compscitech.2006.03.032

[4] Pereira A. B., de Morais A. B., de Moura M. F. S. F., Magalhães A. G.: Mode I interlaminar fracture of woven glass/epoxy multidirectional laminates. Composites Part A: Applied Science and Manufacturing, 36, 1119-1127 (2005).

DOI: $10.1016 /$ j.compositesa.2005.01.006

[5] Pereira A. B., de Morais A. B.: Mode I interlaminar fracture of carbon/epoxy multidirectional laminates. Composites Science and Technology, 64, 2261-2270 (2004).

DOI: $10.1016 /$ j.compscitech.2004.03.001

[6] de Morais A. B., de Moura M. F., Marques A. T., de Castro P. T.: Mode-I interlaminar fracture of carbon/ epoxy cross-ply composites. Composites Science and Technology, 62, 679-686 (2002).

DOI: 10.1016/S0266-3538(01)00223-8

[7] Arai M., Noro Y., Sugimoto K-I., Endo M.: Mode I and mode II interlaminar fracture toughness of CFRP laminates toughened by carbon nanofiber interlayer. Composites Science and Technology, 68, 516-525 (2008).

DOI: $10.1016 /$ j.compscitech.2007.06.007

[8] Kostopoulos V., Tsotra P., Karapappas P., Tsantzalis S., Vavouliotis A., Loutas T. H., Paipetis A., Friedrich K., Tanimoto T.: Mode I interlaminar fracture of CNF or/and PZT doped CFRPs via acoustic emission monitoring. Composites Science and Technology, 67, 822828 (2007). DOI: $10.1016 /$ j.compscitech.2006.02.038

[9] Sadeghian R., Gangireddy S., Minaie B., Hsiao K-T.: Manufacturing carbon nanofibers toughened polyester/glass fiber composites using vacuum assisted resin transfer molding for enhancing the mode-I delamination resistance. Composites Part A: Applied Science and Manufacturing, 37, 1787-1795 (2006).

DOI: 10.1016/j.compositesa.2005.09.010

[10] Yokozeki T., Iwahori Y., Ishibashi M., Yanagisawa T., Imai K., Arai M., Takahashi T., Enomoto K.: Fracture toughness improvement of CFRP laminates by dispersion of cup-stacked carbon nanotubes. Composites Science and Technology, 69, 2268-2273 (2009). DOI: $10.1016 /$ j.compscitech.2008.12.017

[11] Davis D. C., Whelan B. D.: An experimental study of interlaminar shear fracture toughness of a nanotube reinforced composite. Composites Part B: Engineering, 42, 105-116 (2011).

DOI: $\underline{10.1016 / \text { j.compositesb.2010.06.001 }}$
[12] Seyhan A. T., Tanoglu M., Schulte K.: Mode I and mode II fracture toughness of E-glass non-crimp fabric/ carbon nanotube (CNT) modified polymer based composites. Engineering Fracture Mechanics, 75, 51515162 (2008).

DOI: $10.1016 /$ j.engfracmech.2008.08.003

[13] Wicks S. S., de Villoria R. G., Wardle B. L.: Interlaminar and intralaminar reinforcement of composite laminates with aligned carbon nanotubes. Composites Science and Technology, 70, 20-28 (2010).

DOI: 10.1016/j.compscitech.2009.09.001

[14] Li Y., Hori N., Arai M., Hu N., Liu Y., Fukunaga H.: Improvement of interlaminar mechanical properties of CFRP laminates using VGCF. Composites Part A: Applied Science and Manufacturing, 40, 2004-2012 (2009).

DOI: 10.1016/j.compositesa.2009.09.002

[15] Siddiqui N. A., Woo R. S. C., Kim J-K., Leung C. C. K., Munir A.: Mode I interlaminar fracture behavior and mechanical properties of CFRPs with nanoclayfilled epoxy matrix. Composites Part A: Applied Science and Manufacturing, 38, 449-460 (2007).

DOI: 10.1016/j.compositesa.2006.03.001

[16] Phonthammachai N., Li X., Wong S., Chia H., Tjiu W. W., He C.: Fabrication of CFRP from high performance clay/epoxy nanocomposite: Preparation conditions, thermal-mechanical properties and interlaminar fracture characteristics. Composites Part A: Applied Science and Manufacturing, 42, 881-887 (2011). DOI: 10.1016/j.compositesa.2011.02.014

[17] Xu Y., Hoa S. V.: Mechanical properties of carbon fiber reinforced epoxy/clay nanocomposites. Composites Science and Technology, 68, 854-861 (2008).

DOI: 10.1016/j.compscitech.2007.08.013

[18] Ye Y., Chen H., Wu J., Chan C. M.: Interlaminar properties of carbon fiber composites with halloysite nanotube-toughened epoxy matrix. Composites Science and Technology, 71, 717-723 (2011).

DOI: 10.1016/j.compscitech.2011.01.018

[19] Argüelles A., Viña J., Canteli A. F., Castrillo M. A., Bonhomme J.: Interlaminar crack initiation and growth rate in a carbon-fibre epoxy composite under mode-I fatigue loading. Composites Science and Technology, 68, 2325-2331 (2008).

DOI: $10.1016 /$ j.compscitech.2007.09.012

[20] Hojo M., Ando T., Tanaka M., Adachi T., Ochiai S., Endo Y.: Modes I and II interlaminar fracture toughness and fatigue delamination of CF/epoxy laminates with self-same epoxy interleaf. International Journal of Fatigue, 28, 1154-1165 (2006).

DOI: $10.1016 /$ j.ijfatigue.2006.02.004

[21] Hojo M., Matsuda S., Tanaka M., Ochiai S., Murakami A.: Mode I delamination fatigue properties of interlayer-toughened CF/epoxy laminates. Composites Science and Technology, 66, 665-675 (2006). DOI: 10.1016/j.compscitech.2005.07.038 
[22] Boudenot J-C.: New concepts for nanophotonics and nano-electronics: From transistor to nanotube. Comptes Rendus Physique, 9, 41-52 (2008).

DOI: $10.1016 /$ j.crhy.2007.12.002

[23] Kannan A. M., Kanagala P., Veedu V.: Development of carbon nanotubes based gas diffusion layers by in situ chemical vapor deposition process for proton exchange membrane fuel cells. Journal of Power Sources, 192, 297-303 (2009).

DOI: 10.1016/j.jpowsour.2009.03.022

[24] Avilés F., Cauich-Rodríguez J. V., Rodríguez-González J. A., May-Pat A.: Oxidation and silanization of MWCNTs for MWCNT/vinyl ester composites. Express Polymer Letters, 5, 766-776 (2011). DOI: 10.3144/expresspolymlett.2011.75

[25] Zhang Z., Peng K., Chen Y.: Mechanical performance of ozone functionalized MWCNTs/PC nanocomposites. Express Polymer Letters, 5, 516-525 (2011). DOI: $10.3144 /$ expresspolymlett.2011.50

[26] Romhány G., Szebényi G.: Interlaminar crack propagation in MWCNT/fiber reinforced hybrid composites. Express Polymer Letters, 3, 145-151 (2009). DOI: $10.3144 /$ expresspolymlett.2009.19

[27] Ren Y., Li F., Cheng H-M., Liao K.: Tension-tension fatigue behavior of unidirectional single-walled carbon nanotube reinforced epoxy composite. Carbon, 41, 2177-2179 (2003). DOI: $10.1016 / S 0008-6223(03) 00248-3$
[28] Ren Y., Fu Y. Q., Liao K., Li F., Cheng H. M.: Fatigue failure mechanisms of single-walled carbon nanotube ropes embedded in epoxy. Applied Physics Letters, 84, 2811-2813 (2004).

DOI: $10.1063 / 1.1703837$

[29] Zhang W., Picu R. C., Koratkar N.: Suppression of fatigue crack growth in carbon nanotube composites. Applied Physics Letters, 91, 193109/1-193109/3 (2007).

DOI: $10.1063 / 1.2809457$

[30] Grimmer C. S., Dharan C. K. H.: High-cycle fatigue of hybrid carbon nanotube/glass fiber/polymer composites. Journal of Materials Science, 43, 4487-4492 (2008).

DOI: $10.1007 / \mathrm{s} 10853-008-2651-9$

[31] Romhány G., Szebényi G.: Preparation of MWCNT reinforced epoxy nanocomposite and examination of its mechanical properties. Plastics, Rubber and Composites, 37, 214-218 (2008). DOI: $10.1179 / 174328908 X 309376$

[32] Szekrényes A.: Delamination of composite specimens. $\mathrm{PhD}$ thesis, BME, Faculty of Mechanical Engineering, Department of Applied Mechanics (2005).

[33] Romhány G., Szebényi G.: Preparation of MWCNT/ carbon fabric reinforced hybrid nanocomposite and examination of its mechanical properties. Materials Science Forum, 589, 269-274 (2008).

DOI: 10.4028/www.scientific.net/MSF.589.269 